\title{
FACTORES PRONÓSTICO EN CARCINOMA RENAL pT3
}

\author{
D. SÁNCHEZ ZALABARDO, J. AROCENA GARCÍA-TAPIA, J.M. REGOJO BALBOA, \\ J.M. FERNÁNDEZ MONTERO, J. LÓPEZ FERRANDIS, D. ROSELL COSTA, \\ J.E. ROBLES GARCÍA, J.J. ZUDAIRE BERGERA, J.M. BERÍAN POLO
}

Departamento de Urología. Clínica Universitaria. Universidad de Navarra.

Actas Urol Esp. 27 (1): 26-32, 2003

\section{RESUMEN}

"FACTORES PRONÓSTICO EN CARCINOMA RENAL PT3"

OBJETIVO: Valorar los distintos factores pronóstico en relación con la progresión de la enfermedad y con la supervivencia global. Realización de grupos de riesgo según la agrupación de factores de riesgo.

MATERIAL Y MÉTODOS: 117 pacientes que presentaban estadio pT3 (TNM 1997) en la pieza de nefrectomía. Ochenta y ocho pacientes no presentaban enfermedad metastásica en el momento del diagnóstico. La forma de presentación más frecuente fue el diagnóstico casual de tumores asintomáticos. Ochenta pacientes fueron varones (69\%) y 37 mujeres (31\%). Edad media 59 años (rango 24-82). Mediana de seguimiento 34 meses (media $44 \pm 39$ meses).

RESULTADOS: Estadio patológico; pT3a 51 pacientes (43,6\%), pT3b 63 pacientes $(53,6 \%$ y pT3c 3 pacientes. Variantes anatomo-patológicas; carcinoma de células claras (incluyendo variedad sarcomatoide) 106 pacientes (90,6\%), papilar 5 pacientes $(4,3 \%)$ y cromófobo 4 pacientes $(3,4 \%)$. Siguiendo la clasificación de Fuhrman, 13 pacientes presentaron grado 1, 45 pacientes grado 2, 32 pacientes grado 3 y 12 pacientes grado 4. El tamaño, el grado, la afectación ganglionar, y las metástasis se mantuvieron como factores independientes en la progresión en la supervivencia global de los pacientes pT3. Los pacientes no metastásicos con ningún o un factor de mal pronóstico presentan mayor supervivencia global que los pacientes con dos o tres factores pronóstico y que los pacientes metastásicos.

CONCLUSIONES: El tamaño, la diferenciación celular, el estadio, la afectación ganglionar y la presencia de metástasis son factores influyentes independientes en la aparición de recidivas y en la supervivencia global de los pacientes pT3.

El sub-estadio patológico no es factor independiente de progresión de la enfermedad en el estudio multivariado ni influye en la supervivencia global de estos pacientes.

Los pacientes estadio pT3 con dos o tres factores de riesgo no presentan diferencias significativas en la supervivencia cuando se comparan con los pacientes metastásicos.

PALABRAS CLAVE: Carcinoma renal. Estadio pT3. Factores pronósticos.

\section{ABSTRACT}

"PROGNOSIS FACTORS IN pT3 RENAL CELL CARCINOMA"

OBJECTIVES: To identify independent predictors of progression and global survival in patients affected by pT3 renal cell carcinoma. To make risk groups by risk factors.

MATERIAL AND METHODS: We evaluated 117 patients with pT3 renal cell carcinoma. 88 was MO and 29 M1. Most frecuent clinical feature: asintomatic patiens. 80 males (69\%) and 37 females (31\%). Mean age 59 (24-82). Median follow up 34 monthsw (mean $44 \pm 39$ months).

RESULTS: Pathological stage (TNM 1997) was pT3a in 52 patients (43.6\%), pT3b 63 patients (53.6\%) and pT3c 2 patients. Histology: clear cell carcinoma 106 patients (90.6\%), papillary 5 patients (4.3\%) an dchromophobe 4 patients (3.4\%). Nuclear grading according Fuhrman's classification: G1 13 patients, G2 45 patients, G3 32 and G4 12 patients.

Size $>4 \mathrm{~cm}(\mathrm{p}=0.005 / \mathrm{p}=0.0019)$, grade 3-4 ( $=0.006 / \mathrm{p}=0.0007), \mathrm{N}+(\mathrm{p}=0.034 / \mathrm{p}=0.009)$ and $\mathrm{M}+(\mathrm{p}=0.035 /$ $\mathrm{p}=0.042$ ) were independent prognosis factors for progression and global survival of the pT3 renal cell carcinoma. Patiens MO with 0 or 1 risk factor have better global survival tanh patiens M0 with 3 or 4 risk factors and patiens M1.

CONCLUSIONS: Size, grade, $\mathrm{N}+$ and $\mathrm{M}+$ were independent prognosis factors for progression and global survival of the pT3 renal cell carcinoma. Tera are no differencias in global survival betwen patients MO with 2 or 3 risk factors and patients M1.

KEY WORDS: Renal cell carcinoma. PT3. Prognosis factors. 
$\mathrm{E}_{\mathrm{d}}^{\mathrm{a}}$ carcinoma renal (CR) aparece con una incidencia de 4-6 casos/100.000 habitantes y representa más del 90\% de los tumores del parénquima renal. En la mayoría de los casos tiene su origen en las células del túbulo contorneado proximal, aunque existen variantes anatomo-patológicas como el carcinoma cromófobo y el tumor de túbulos colectores que proceden de la médula renal $^{1}$. En el momento del diagnóstico el 20-30\% de los pacientes suele presentar metástasis.

Para el estadiaje de los tumores renales, se utilizan fundamentalmente dos clasificaciones:

- Clasificación por estadios de Robson

- Clasificación TNM de la UICC (última revisión de 1997)

En la clasificación TNM 1997, los pT3 incluyen tumores que afectan a la grasa perirrenal o suprarrenal ipsilateral (pT3a) o invaden la vena renal, cava o aurícula derecha (pT3b-c).

El diagnóstico del carcinoma renal ha variado sustancialmente en los últimos años, siendo cada vez más frecuente el diagnóstico incidental ${ }^{2,3}$ durante el curso de exploraciones complementarias por una enfermedad no relacionada o durante una ecografia realizada como chequeo. Las últimas publicaciones registran un aumento del 15-20\% en el diagnóstico incidental del $\mathrm{CR}$ aunque este aumento de incidencia afecta a todos los estadios ${ }^{4}$. Cuando debuta con sintomatología, el signo más frecuente es la hematuria, aunque ésta tiene una escasa sensibilidad ya que sólo el $0,6 \%$ de los pacientes con hematuria presentan un tumor renal ${ }^{5}$.

Estudiamos los pacientes intervenidos por carcinoma renal en los que el estadio patológico estaba incluido dentro del estadio pT3 de la clasificación TNM 1997 de la UICC, así como los factores pronóstico influyentes en la progresión de la enfermedad tras la nefrectomía y/o en la supervivencia global de estos pacientes.

\section{MATERIAL Y MÉTODOS}

De las 319 nefrectomías por carcinomas renales, realizadas desde 1980 a diciembre de 2000 , se estudian 117 pacientes que presentaban estadio pT3 (TNM 1997) en la pieza de nefrectomía. Se revisó el estadio patológico de los pacientes intervenidos con anterioridad a 1997 y se recodificó con relación a la última revisión de la clasificación TNM de la UICC.
Ochenta pacientes fueron varones (69\%) y 37 mujeres (31\%). Edad media 59 años (rango 24-82). Mediana de seguimiento 34 meses (media $44 \pm 39$ meses).

La forma de presentación más frecuente fue el diagnóstico casual de tumores asintomáticos (35\%) diagnosticados tras la realización de exploraciones radiológicas por otras causas. Cuando presentan sintomatología, la hematuria es la clínica más frecuente $(29,1 \%$ de los pacientes) seguida de la aparición de un sindrome constitucional (13,7\% de los pac.). En todos los pacientes (independientemente de la forma de presentación) se realizó un TAC abdomino-pélvico y una gammagrafía ósea de estadiaje. En los pacientes con sospecha de afectación de la cava se realizó una resonancia magnética para valorar la longitud del trombo.

Ochenta y ocho pacientes no presentaban enfermedad metastásica en el momento del diagnóstico (12 pacientes presentaban afectación ganglionar sin metástasis a distancia en el momento del diagnóstico) y 29 pacientes $(24,8 \%)$ presentaban metástasis en el momento del diagnóstico.

Se realizaron 112 nefrectomías ampliadas y 5 nefrectomías parciales. En los dos pacientes con afectación supradiafragmática se realizó la extracción del trombo tumoral mediante atriotomía derecha y con circulación extracorpórea.

Se consideró progresión de la enfermedad a la aparición de tumor tras la nefrectomía en pacientes no metastásicos o a la aparición de nuevas metástasis en pacientes metastásicos.

En el análisis estadístico se utilizó un estudio de regresión logistica binaria univariado y multivariado para la identificación de los factores influyentes en la progresión de la enfermedad, análisis de supervivencia de Kaplan-Meier (con comparación de supervivencia de Log-Rank) y un análisis de regresión de Cox para la identificación de factores influyentes en la supervivencia.

\section{RESULTADOS}

Las características clínico-patológicas se resumen en la Tabla I.

El estadio más frecuente fue el estadio pT3b que afectó a 63 pacientes (53,6\%), pT3a 51 pacientes $(43,6 \%)$ y pT3c 3 pacientes. Para el análisis estadístico se agruparon los estadios pT3 b y c. 
TABLA I

CARACTERÍSTICAS CLÍNICO-PATOLÓGICAS

\begin{tabular}{|c|c|}
\hline & № pacientes (\%) \\
\hline Edad & \\
\hline Media (rango) & 59 años (24-82) \\
\hline Hombres/mujeres & $80 / 37(69 / 31)$ \\
\hline Clínica & \\
\hline Asintomáticos & $41(35)$ \\
\hline Hematuria & $34(29)$ \\
\hline Masa lumbar & $1(0,9)$ \\
\hline Sdme constitucional & $16(13)$ \\
\hline Otros & $10(8,5)$ \\
\hline \multicolumn{2}{|l|}{ Metástasis } \\
\hline No & $88(75,2)$ \\
\hline $\mathrm{Si}$ & $29(24,8)$ \\
\hline \multicolumn{2}{|l|}{ Variedad A.P. } \\
\hline C. Claras & $106(90,6)$ \\
\hline Cromófobo & $4(3,4)$ \\
\hline C. Papilar & $5(4,3)$ \\
\hline \multicolumn{2}{|l|}{ PT3 } \\
\hline A & $51(43,6)$ \\
\hline B & $63(53,8)$ \\
\hline $\mathrm{C}$ & $3(2,6)$ \\
\hline \multicolumn{2}{|l|}{ Diferenciación celular } \\
\hline G1 & $13(11,1)$ \\
\hline G2 & $45(38,5)$ \\
\hline G3 & $32(27,4)$ \\
\hline G4 & $12(10,3)$ \\
\hline \multicolumn{2}{|l|}{ Tamaño } \\
\hline$<4 \mathrm{~cm}$ & $15(12,8)$ \\
\hline$>4 \mathrm{~cm}$ & $94(80,3)$ \\
\hline \multicolumn{2}{|l|}{ Afectación ganglionar } \\
\hline $\mathrm{Si}$ & $30(25,6)$ \\
\hline No & $79(67,5)$ \\
\hline
\end{tabular}

Las distintas variantes anatomo-patológicas fueron: carcinoma de células claras (incluyendo variedad sarcomatoide) 106 pacientes $(90,6 \%)$, papilar 5 pacientes $(4,3 \%)$ y cromófobo 4 pacientes $(3,4 \%)$. En dos casos no se pudo determinar la variedad histológica.

Siguiendo la clasificación de Fuhrman, 13 pacientes presentaron grado 1, 45 pacientes grado 2,32 pacientes grado 3 y 12 pacientes grado 4 . En el resto de los pacientes no se especificó la diferenciación célular del tumor.

El tamaño medio del tumor fue de $7,8 \mathrm{~cm}$ (rango 1,5-15 cm). Se tomó como punto de corte 4 $\mathrm{cm}$ por ser el mejor punto de corte en nuestra serie. 23 pacientes $(19,7 \%)$ presentaban tumores menores de $4 \mathrm{~cm}$ y 94 pacientes $(80,3 \%)$ presentaban tumores mayores de $4 \mathrm{~cm}$.

En 30 pacientes $(25,6 \%)$ existía afectación tumoral de los ganglios linfáticos (pN+). En 8 pacientes no se obtuvieron ganglios para su análisis (5 nefrectomías parciales y 3 nefrectomías ampliadas).

Durante el seguimiento, 61 pacientes $(52,1 \%)$ han presentado progresión o recidiva del tumor tras el tratamiento. Al final del seguimiento han fallecido 54 pacientes (46,2\%), 53 pacientes están vivos $(45,3 \%)$ y 10 pacientes se han perdido.

Factores influyentes en la progresión de la enfermedad

1. Estudio univariado (Tabla II)

Se estudiaron 7 variables clínico-patológicas dicotomizadas y se realizó un estudio de regresión logística binomial.

Las variables a estudio fueron: diferenciación celular (G1-2 vs G3-4), estadio patológico (pT3a vs pT3b/c), tamaño del tumor $(<4 \mathrm{~cm} v s>4 \mathrm{~cm})$, variedad celular (células claras vs otros), afectación ganglionar ( $\mathrm{pN}-v s \mathrm{pN}+$ ), el diagnóstico incidental (asintomático vs síntomas) y la presencia de metástasis en el momento del diagnóstico (Mvs $\mathrm{M}+$ ).

El grado $(\mathrm{p}=0,01)$, el estadio $(\mathrm{p}=0,01)$, el tamaño $(\mathrm{p}=0,02)$, la afectación ganglionar $(\mathrm{p}=0,02)$ y las metástasis $(\mathrm{p}<0,01)$ fueron factores influyentes en la progresión de la enfermedad. La variedad anatomopatológica $(\mathrm{p}=0,09)$ y el diagnóstico incidental $(p=0,12)$ no presentaron influencia estadísticamente significativa en la progresión de la enfermedad.

\section{TABLA II}

FACTORES INFLUYENTES EN LA PROGRESIÓN DE LA ENFERMEDAD. ESTUDIO UNIVARIADO

\begin{tabular}{||l|c|c||}
\hline & $\operatorname{Exp}(\mathrm{B}) \mathrm{I} . \mathrm{C}$. & sig. \\
\hline Grado 3-4 & $3,34(1,2-8,7)$ & $\mathbf{0 , 0 1 3}$ \\
pT3 b-c & $2,96(1,2-7,3)$ & $\mathbf{0 , 0 1 8}$ \\
Tamaño >4 cm & $6,18(1,2-29,8)$ & $\mathbf{0 , 0 2 3}$ \\
Var A.P. c. claras & $3,29(0,8-13)$ & 0,09 \\
pN+ & $3,24(1-9)$ & $\mathbf{0 , 0 3 3}$ \\
Incidental & $1,85(0,8-4,3)$ & 0,12 \\
M+ & $8,44(2,3-30,3)$ & $\mathbf{0 , 0 0 1}$ \\
\hline
\end{tabular}




\section{Estudio multivariado (Tabla III)}

Se realizó un estudio de regresión logística binaria multivariado con los factores influyentes en el estudio univariado. El tamaño $(p=0,005)$, el grado $(p=0,006)$, la afectación ganglionar $(\mathrm{p}=0,034)$, y las metástasis $(\mathrm{p}=0,035)$ se mantuvieron como factores independientes en la progresión de la enfermedad. Mientras que el estadio patológico (a $v s \mathrm{~b} / \mathrm{c}$ ) no aparece como factor independiente $(\mathrm{p}>0,05)$.

\section{TABLA III}

FACTORES INFLUYENTES EN LA PROGRESIÓN DE LA ENFERMEDAD. ESTUDIO MULTIVARIADO

\begin{tabular}{|l|c|c|c|c||}
\hline & $\mathrm{B}$ & $\operatorname{Exp}(\mathrm{B})$ & $95 \% \mathrm{CI} \operatorname{Exp}(\mathrm{B})$ & Sig. \\
\hline Tamaño $>4$ & 2,57 & 13,14 & $2,12-81,27$ & 0,0056 \\
\hline Grado 3-4 & 1,49 & 4,47 & $1,51-13,26$ & 0,0068 \\
\hline $\mathrm{N}+$ & 1,46 & 4,32 & $1,11-16,81$ & 0,034 \\
\hline $\mathrm{M}+$ & 1,33 & 3,80 & $1,08-16,57$ & 0,035 \\
\hline
\end{tabular}

Factores influyentes en la supervivencia global Estudio de supervivencia Kaplan-Meier (Figs. $1,2,3$ y 4 )

El tamaño tumoral $(p=0,002)$, la afectación ganglionar $(\mathrm{p}<0,0001)$, la presencia de metástasis $(p<0,0001)$ y el grado tumoral $(p=0,0001)$, se presentan como los factores influyentes en la supervivencia global de estos factores.

El estadio patológico $(\mathrm{p}=0,12)$ y el diagnóstico incidental $(\mathrm{p}=0,11)$ no tienen una influencia estadísticamente significativa en la supervivencia global.

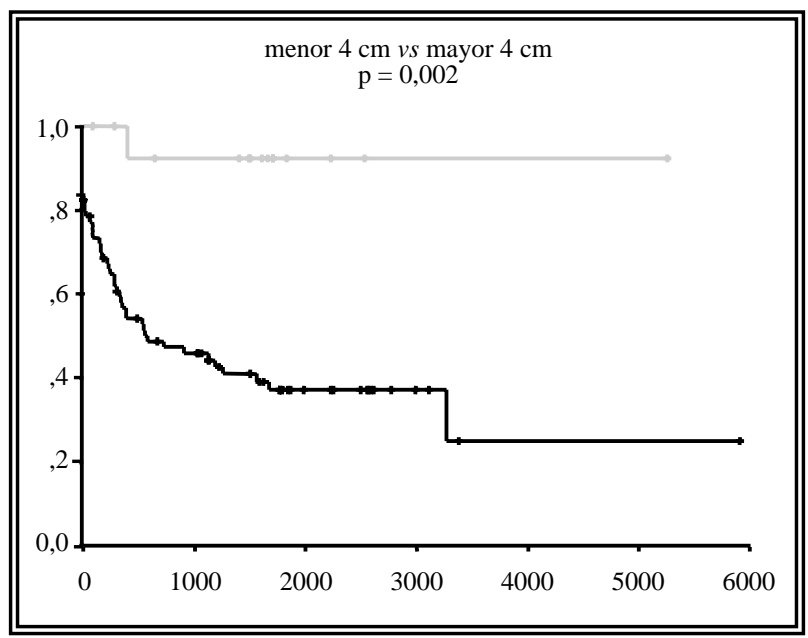

FIGURA 1. Supervivencia $<4 \mathrm{~cm}$ vs $>4 \mathrm{~cm}$.

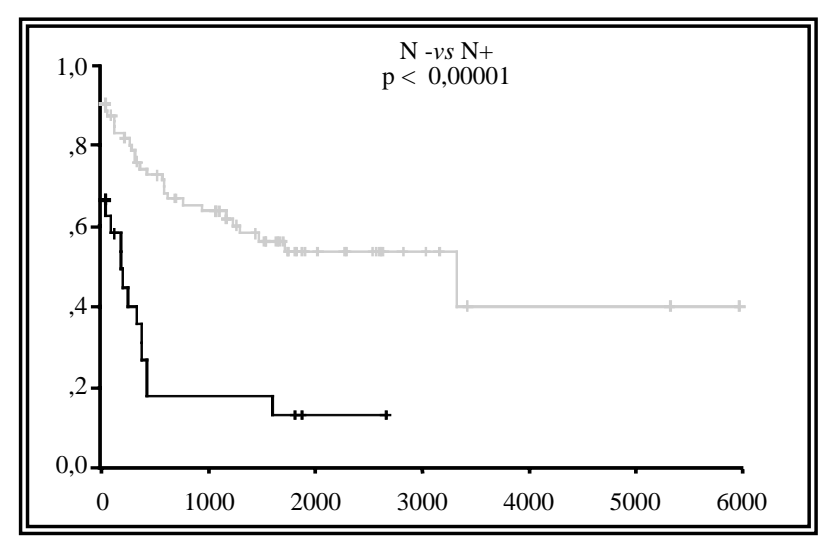

FIGURA 2. Supervivencia $\mathrm{N}$ - vs $\mathrm{N}+$

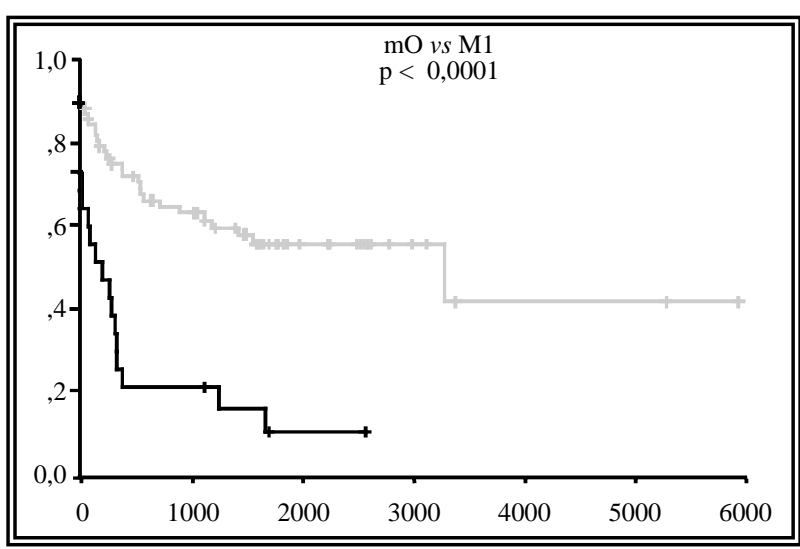

FIGURA 3. Supervivencia MO vs M1.

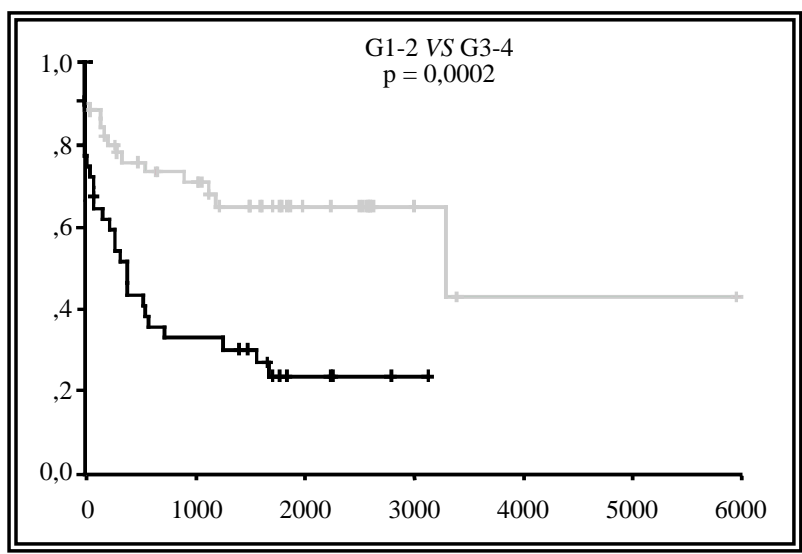

FIGURA 4. Supervivencia G1-2 vs G3-4.

Estudio de regresión de Cox (Tabla IV)

Estudiando las seis variables utilizadas en los estudios de Kaplan-Meier, se mantienen como factores independientes de supervivencia el tamaño tumoral $(p=0,019)$, la afectación ganglionar $(\mathrm{p}=0,009)$, la presencia de metástasis $(\mathrm{p}=0,042)$ y el grado $(\mathrm{p}=0,0007)$. 
TABLA IV

FACTORES INDEPENDIENTES INFLUYENTES EN LA SUPERVIVENCIA GLOBAL. ESTUDIO DE COX

\begin{tabular}{|l|c|c|c||}
\hline & B & $\operatorname{Exp(B)~(S.E)~}$ & Sig. \\
\hline Grado & 1,18 & $3,25( \pm 0,34)$ & 0,0007 \\
\hline Tamaño & 2,37 & $10,73( \pm 1,01)$ & 0,019 \\
\hline PN & 1,35 & $2,39( \pm 0,33)$ & 0,009 \\
\hline M & 1,66 & $2,02( \pm 0,34)$ & 0,042 \\
\hline
\end{tabular}

\section{Realización de grupos de riesgo}

Se agruparon los pacientes según la presencia de los factores de riesgo independientes en tres grupos:

Grupo I: Pacientes con enfermedad metastásica en el momento del diagnóstico.

Grupo II: Pacientes con dos o tres factores de mal pronóstico (tumor $>4 \mathrm{~cm}, \mathrm{G} 3 / 4$ y/o N+).

Grupo III: Pacientes con ningún o un factor de mal pronóstico.

La supervivencia a 5 años para los grupos I, II y III fue del 15\%, 30\%, y $81 \%$ con una media de supervivencia de 2,7, 3,5 y 13 años respectivamente.

Se realizó un estudio de supervivencia de Kaplan-Meier en el que se observaron diferencias significativas en la supervivencia comparando el grupo III con los grupos II y I ( $\mathrm{p}<0,00001)$. No existen diferencias significativas cuando se comparan los pacientes del grupo I y II.

\section{DISCUSIÓN}

En la última revisión de la clasificación TNM de la UICC de 1997, se definen como tumores renales estadio pT3 aquellos tumores que afectan a la glándula suprarrenal, a los tejidos perirrenales sin sobrepasar la fascia de Gerota o a los tumores renales que invaden la vena renal. El estadio pT3 se subdivide en estadio pT3a cuando no hay afectación de la vena renal, pT3b si afecta a la vena renal o cava inferior por debajo del diafragma y pT3c cuando se extiende por encima del diafragma ${ }^{6}$.

Los cambios respecto al estadio pT3 comparando esta clasificación con la de 1992, se centran en los tumores que afectando a la cava sobrepasan el diafragma, que han pasado de ser estadio pT4 a ser pT3c y los que afectan a la cava por debajo del diafragma que pasan a clasificarse como pT3b (en la clasificación TNM 1992 eran pT3c). Con estas modificaciones, se ha conseguido mayor uniformidad pronóstica en los pacientes con afectación vascular, sea cual sea su extensión ${ }^{7}$.

Los factores pronóstico más importantes en los carcinomas renales son la presencia de metástasis en el momento del diagnóstico, el estadio patológico, el grado tumoral, la variedad anatomopatológica del tumor y el estado general previo a la nefrectomía ${ }^{8,9}$.

En la última década se ha estudiado la relación de distintos marcadores tumorales con la progresión y la supervivencia global tras el tratamiento inicial, así como su posible influencia en la respuesta tumoral a los distintos tratamientos complementarios.

Existe un amplio abanico de pequeños estudios que valoran múltiples alteraciones moleculares con el pronóstico de tumores renales. Los más frecuentemente estudiados son:

- Morfometría nuclear (área nuclear) ${ }^{10-12}$.

- Alteraciones del ADN tumoral (ploidía, pérdida de heterozigosidad) ${ }^{13,14}$.

- Alteración en la expresión de p53 ${ }^{15,16}$.

- Expresión de CD44 y CD44v6 $6^{17,18}$.

- Actividad de células TIL (CD8+) ${ }^{19}$.

- Factor de crecimiento endotelial ${ }^{20}$.

- Invasión microvascular ${ }^{21,22}$.

Estos factores no son utilizados de forma generalizada en la práctica clínica diaria ya que existen múltiples estudios que dudan de su eficacia $^{16,23}$ debiendo realizarse estudios prospectivos de mayor envergadura, ya que en pocos casos son factores independientes, estando relacionados con otros factores clínico-patológicos (fundamentalmente con el grado nuclear de Fuhrman).

En nuestra serie estudiamos, dentro de los carcinomas renales pT3, los factores pronóstico clínico-patológicos que influyen en la progresión (o recidiva) de la enfermedad y en la supervivencia global de la misma.

La presencia de sintomatología es un factor de mal pronóstico frente a los tumores incidentales diagnosticados tras la realización de alguna prueba de imagen por otra causa ${ }^{2,24}$. Las alteraciones analíticas más frecuentes son el aumento de la velocidad de sedimentación (VSG), la presencia de anemia, la hipercalcemia y el aumento de la fos- 
fatasa alcalina. Estas alteraciones analíticas junto con la pérdida de peso (>10\%) suelen asociarse a metástasis en el momento del diagnóstico.

La diferenciación celular se relaciona en todos los estudios tanto con la supervivencia como con la tasa de progresión del tumor renal. Existen distintas clasificaciones para valorar la diferenciación celular, siendo la clasificación del grado nuclear de Fuhrman la más frecuentemente utilizada ${ }^{25}$. La influencia pronóstica del grado nuclear es más significativa cuando se agrupan los tumores bien diferenciados (G1 y G2 de Fuhrman) y los tumores indiferenciados (G3 y G4 de Fuhrman) ${ }^{26,27}$.

La clasificación histopatológica de los carcinomas renales se basa en factores genéticos. Los carcinomas renales, siguiendo esta clasificación, se dividen en carcinomas de células claras, carcinoma papilar renal, carcinoma cromófobo, carcinoma de los túbulos colectores y carcinoma renal no clasificable ${ }^{28}$. Tanto los carcinomas cromófobos como los papilares suelen presentar un menor estadio y número de metástasis en el momento del diagnóstico, por lo que la supervivencia en este tipo de tumores es mayor que en los carcinomas de células claras ${ }^{29,30}$. En nuestra serie, la variedad anatomo-patológica no tiene valor pronóstico independiente en la progresión ni en la supervivencia de la enfermedad. Dentro de los tumores de células claras existen dos subtipos con características propias y de comportamiento opuesto. Los tumores quísticos presentan generalmente un estadio y un grado menor que los tumores de células claras clásicos ${ }^{31}$. Los tumores sarcomatoides son los de peor pronóstico dentro de los carcinomas de células claras fundamentalmente por su indiferenciación celular y su alto grado nuclear, aunque se han descrito tumores renales de células fusiformes de bajo grado nuclear (grado 2 de Fuhrman) que presentan mejor pronóstico que el carcinoma sarcomatoide clásico ${ }^{32}$.

Dentro del estadio patológico, los pacientes con invasión vascular tienen un mayor porcentaje de recidivas, aunque no se asocia a una menor supervivencia $^{33-35}$. En nuestros pacientes, coincidiendo con publicaciones anteriores, la afectación vascular provoca una mayor tasa de progresión de la enfermedad que la afectación de la grasa perirrenal o de la suprarrenal, pero en el análisis de supervivencia no hay diferencias significativas entre los dos grupos. Del mismo modo, en el estudio multivariado el estadio (pT3a vs pT3b-c) no es un factor pronóstico independiente manteniéndose el grado nuclear, la afectación ganglionar, la presencia de metástasis en el momento del diagnóstico y el tamaño mayor de $4 \mathrm{~cm}$ como factores independientes. Estos mismos factores tienen un valor independiente en el pronóstico de recidiva o progresión de la enfermedad.

Con los factores pronóstico independientes se agruparon los pacientes en distintos grupos según presenten metástasis en el momento del diagnóstico (Grupo I) o no las presenten. Este segundo grupo se dividió en relación con el número de factores de mal pronóstico (G3-4, tamaño $>4 \mathrm{~cm}$ y/o $\mathrm{pN}+$ ). Combinando estos factores se obtuvieron dos grupos: pacientes con ningún o un factor de riesgo (Grupo II) y pacientes con dos o los tres factores de mal pronóstico (Grupo III). En nuestros pacientes se observa una mayor supervivencia del grupo III con respecto a los otros dos, pero no existen diferencias significativas entre la supervivencia de los grupos I y II.

La realización de grupos de riesgo, pueden facilitar la selección de pacientes candidatos a recibir inmunoterapia así como valorar la respuesta del tratamiento en cada grupo.

\section{CONCLUSIONES}

El tamaño, la diferenciación celular, el estadio, la afectación ganglionar y la presencia de metástasis son factores influyentes independientes en la aparición de recidivas y en la supervivencia global de los pacientes pT3.

El sub-estadio patológico no es factor independiente de progresión de la enfermedad en el estudio multivariado ni influye en la supervivencia global de estos pacientes.

Los pacientes estadio pT3 con dos o tres factores de riesgo no presentan diferencias significativas en la supervivencia cuando se comparan con los pacientes metastásicos.

\section{REFERENCIAS}

1. NAGASHIMA Y.: Chromophobe renal cell carcinoma: clinical, pathological and molecular biological aspects. Pathol Int 2000; 50 (11): 872-878.

2. KE-HUNG TSUI, OLEG SHVARTS, SMITH ROBERT B et al.: Renal cell carcinoma: prognostic significance of incidentally detected tumors. J Urol 2000; 163: 426-430. 
3. RUSSO P.: Renals cell carcinoma: presentation, staging, and surgical treatment. Semin Oncol 2000; 27 (2): 160176.

4. HOCK LM, LYNCH J, BALAJI KC: Increasing incidence of all stages of kidney cancer in the las decades in the united states: an analysis of surveillance, epidemiology and results program data. J Urol 2002; 167: 57-60.

5. KHADRA MH, PICKARD RS, CHARLTON M, POWEL PG, NEAL DE: A prospective analysis of 1930 patients with hematuria to evaluate current diagnostic practice. $J$ Urol 2000; 163: 524-527.

6. GUINAN P, SOBIN LH, ALGABA F et al.: TNM staging of renal cell carcinoma. Cancer 1997; 80: 992-993.

7. FICARRA V, RIGHETTI R, PILLONI S et al.: Prognostic factors in patients with renal cell carcinoma: retrospective analisis of 675 cases. Eur Urol 2002; 41: 190-198.

8. TSUI K, SHVARTS O, SMITH RB et al.: Prognostic indicators for renal carcinoma: a multivariate analysis of 643 patients using the revised 1997 TNM staging criteria. J Urol 2000; 163: 1.090-1.095.

9. GELB AB.: Renal cell carcinoma. Current prognostic factors. Cancer 1997; 80: 981-986.

10. GUTIÉRREZ JL, VAL-BERNAL JF, GARIJO MF, BUELTA L, PORTILLO JA.: Nuclear morphometry in prognosis of renal adenocarcinoma. Urology 1992; 39 (2): 130134.

11. RUIZ JL, HERNÁNDEZ M, MARTÍNEZ J, VERA C, JIMÉNEZ-CRUZ JF.: Value of morphometry as an independent prognostic factor in renal cell carcinoma. Eur Urol 1995; 27 (1): 54-57.

12. RUIZ CERDÁ JL, HERNÁNDEZ M, GOMIS F y cols.: Value of deoxyribonucleic acid ploidy and nuclear morphometry for prediction of disease progression in renal cell carcinoma. J Urol 1996; 155 (2): 459-465.

13. RUIZ CERDÁ JL, HERNÁNDEZ M, SEMPERE A y cols.: Intratumoral heterogeneity of DNA content in renal cell carcinoma and its prognostic significance. Cancer 1999; 15; 86 (4): 664-671.

14. BERNUES M, CASADEVALL C, MIRO R et al.: Analysis of 3p allelic losses in renal cell carcinomas: comparison with cytogenetic results. Cancer Genet Cytogenet 1998; 107 (2): 121-124.

15. GIRGIN C, TARHAN H, HEKIMGIL M, SEZER A, GUREL G: p53 mutations and other prognostic factors of renal cell carcinoma. Urol Int 2001; 66 (2): 78-83.

16. LJUNGBERG B, BOZOKY B, KOVACS G et al.: p53 expression in correlation to clinical outcome in patients with renal cell carcinoma. Scand J Urol Nephrol 2001; 35: $15-20$

17. DANIEL L, LECHEVALLIER E, GIORGI R et al.: CD44s and CD44v6 expression in localized T1-T2 conventional renal cell carcinomas. J Pathol 2001; 193 (3): 345-349.

18. DE ÁLAVA E, PANIZO A, SOLA I, RODRÍGUEZ-RUBIO FI, PARDO-MINDÁN FJ.: CD44v6 expression is related to progression in renal epithelial tumours. Histopathology 1998; 33 (1): 39-45.

19. NAKANO O, SATO M, NAITO Y et al.: Proliferative activity of intratumoral CD8(+) T-lymphocytes as a prognostic factor in human renal cell carcinoma: clinicopathologic demonstration of antitumor immunity. Cancer Res 2001; 61 (13): 5.132-5.136.

20. PARADIS V, LAGHA NB, ZEIMOURA L et al.: Expression of vascular endothelial growth factor in renal cell carcinomas. Virchows Arch 2000; 436 (4): 351-356.
21. SEVINC M, KIRKALI Z, YORUKOGLU K, MUNGAN U, SADE M.: Prognostic significance of microvascular invasion in localized renal cell carcinoma. Eur Urol 2000; 38 (6): 728-733.

22. LANG H, LINDNER V, SAUSSINE C et al.: Microscopic venous invasion: a prognostic factor in renal cell carcinoma. Eur Urol 2000; 38 (5): 600-605.

23. ZHOU M, RUBIN MA.: Molecular markers for renal cell carcinoma: impact on diagnosis and treatment. Semin Urol Oncol 2001; 19: 80-87.

24. CONGREGADO RUIZ B, MEDINA LÓPEZ RA, SÁNCHEZ GÓMEZ E, MORALES LÓPEZ A, PASCUAL DEL POBIL JL.: Diagnóstico incidental del carcinoma renal. ¿Implica mejor pronóstico?. Actas Urol Esp 2001; 25: 278-282.

25. GOLDSTEIN NS.: The current state of renal cell carcinoma grading. Cancer 1997; 80: 1.977-1.980.

26. MINERVINI A, LILAS L, MINERVINI R, M.D., SELLI C.: Prognostic value of nuclear grading in patients with intracapsular (pT1-pT2) renal cell carcinoma. Cancer 2002; 94 (10): 2.590-2.599.

27. CHEVILLE JC, BLUTE ML, ZINCKE H, LOHSE CM, WEAVER AL.: Stage pT1 conventional (clear cell) renal cell carcinoma: pathological features associated with cancer specific survival. J Urol 2001; 166 (2): 453-456.

28. STRÖRKEL S, EBLE JN, ADLAKHA K et al.: Clasification of renal cell carcinoma. Cancer 1997; 80: 987-989.

29. LJUNGBERG B, ALAMDARI FI, STENLING R, ROOS G.: Prognostic significance of the Heidelberg classification of renal cell carcinoma. Eur Urol 1999; 36 (6): 565-569.

30. SANZ PÉREZ G, AROCENA GARCÍA-TAPIA J, ZUDAIRE BERGERA JJ y cols.: Carcinoma cromófobo de riñón. Actas Urol Esp 1999; 23 (4): 323-326.

31. BIELSA O, LLORETA J, GELABERT-MAS A.: Cystic renal cell carcinoma: pathological features, survival and implications for treatment. Br J Urol 1998; 82 (1): 1620.

32. LLORETA J, COROMINAS JM, MUNNE A, DOMÍNGUEZ D, BIELSA O, GELABERT A, SERRANO S.: Low-grade spindle cell carcinoma of the kidney. Ultrastruct Pathol 1998; 22 (1): 83-90.

33. FICARRA V, RIGHETTI R, D'AMICO A et al.: Renal vein and vena cava involvement does not affect prognosis in patients with renal cell carcinoma. Oncology 2001; 61 (1): 10-15.

34. SÁNCHEZ DE LA MUELA P, ZUDAIRE JJ, ROBLES JE y cols.: Renal cell carcinoma: vena caval invasion and prognosis factors. Eur Urol 1991; 19 (4): 284-290.

35. SÁNCHEZ DE LA MUELA P, ZUDAIRE BERGERA JJ, ROBLES GARCÍA JE y cols.: Análisis de supervivencia en carcinoma renal con invasión de la cava. Actas Urol Esp 1991; 15 (3): 247-252.

Dr. D. Sánchez Zalabardo

Servicio de Urología

Clínica Universitaria de Navarra

Avda. Pío XII, 36

31008 Pamplona (Navarra)

(Trabajo recibido 24 junio de 2002) 